\title{
SERIAL OBSERVATIONS OF FOLLICULAR MORPHOLOGY NEAR OVULATION IN MACACA FASCICULARIS*
}

\author{
D. A. JEWETT and W. R. DUKELOW \\ Endocrine Research Unit, Michigan State University, \\ East Lansing, Michigan 48823, U.S.A.
}

(Received 15th February 1972, accepted 30th May 1972)

\begin{abstract}
Summary. The current investigation adapted photographic techniques to the laparoscope to characterize the morphology of follicular development in Macaca fascicularis. A vascular network was found to emerge on the surface of the ovary $30 \mathrm{hr}$ before ovulation and provided the most reliable indication of follicular development. Within $10 \mathrm{hr}$ of ovulation, a single vessel became established on the centre of the follicular wall. Stigmata were observed on either side of this vessel. Postovulatory follicular changes permitted the diagnosis of ovulation by laparoscopy.
\end{abstract}

With the exception of some excellent cinematographic studies in the rat (Blandau, 1955), few have been able to predict ovulation accurately and photograph the follicular morphology as the time of ovulation approaches. Laparoscopy (Semm, 1969) offers an opportunity for such studies without the trauma associated with laparotomy.

Thirty-one adult female macaque monkeys, Macaca fascicularis, were maintained under controlled temperature and lighting conditions (12 hr light) in the primate colony of the Endocrine Research Unit. All animals had been in captivity for at least 5 years and many had been born in captivity. The cycles of each female were characterized with respect to length, severity and duration of menstrual flow (Jewett \& Dukelow, 1972). The fertility of most of the colony had been established with the birth of approximately twenty offspring in the 2 years immediately preceding the present study, including five pregnancies obtained after exposure to the male for only 20 to $30 \mathrm{~min}$ at the predicted time of ovulation based on laparoscopic examination (Jewett \& Dukelow, 1971b).

Laparoscopic examinations were begun on the 10th day of the menstrual cycle and were continued for 3 to 4 days, at intervals of 4 to $12 \mathrm{hr}$, depending on the follicular development (Jewett \& Dukelow, 1971a). As the time of ovulation approached, laparoscopies were made every $4 \mathrm{hr}$. In three cases, the animals were kept under continuous anaesthesia so that observations could be made every hour for $9 \mathrm{hr}$ in an attempt to observe actual ovulation.

The laparoscope consisted of a Model 4000 projector light source (Richard

* Journal Series Article No. 5702. Approved by the Director, Michigan State University, Agricultural Experiment Station. 
Wolf, GMBH, 7134 Knittlingen, West Germany), a fibre optic cable, and a 135 degree paediatric laparoscope, $5 \mathrm{~mm}$ in diameter. The laparoscope, probes, and trocar-cannula were kept in benzalkonium chloride (Zephiran, Winthrop) before use. Monkeys were anaesthetized with phencyclidine hydrochloride (Sernylan, Bio-Ceutic Laboratories), $0.15 \mathrm{mg} / \mathrm{kg}$ given intramuscularly, and were then placed on their backs on the laparoscopy table, with the stage elevated at 45 degrees (Dukelow, Jarosz, Jewett \& Harrison, 1971). The trocar-cannula was inserted through a $1-\mathrm{cm}$ mid-line incision in the ventral abdomen. The trocar was then withdrawn, and the laparoscope inserted through the cannula. The fibre optic cable and the gas supply hose for abdominal distension were attached to the laparoscope and cannula, respectively. Periodic insufflation, using $5 \% \mathrm{CO}_{2}$ in air passed through a water chamber, was used to distend the abdominal cavity. With the aid of a tactile probe inserted laterally, the organs could be manipulated. No drying effect was observed from the gas and no apparent effect on the follicle development was noted.

In order to obtain satisfactory colour photographs through the laparoscope, several combinations of films, cameras and camera settings were tested. The following cameras were used: Exakta VX 1000; Olympus Pen-F; and, a Canon TL. All cameras were attached to the laparoscope by means of a 95-mm lens adapter. The following types of film were evaluated: Ektachrome EHB; Ektachrome X; Kodachrome X; Kodachrome KPA; and, Anscochrome 500. Shutter speeds ranging from $1 \mathrm{sec}$ to $1 / 100 \mathrm{sec}$ were used with all combinations of film and light intensities. Best results were obtained with Ektachrome EHB at $1 / 8$ to $1 / 15 \mathrm{sec}$ exposure.

A preliminary report of these studies has been presented (Jewett \& Dukelow, 1971a). Laparoscopic observations were made on 129 cycles over an 8-month period.

The site of the developing follicle could be identified 2 days before ovulation by (a) a generalized swelling and darkening of a portion of the ovarian surface, (b) an increase of approximately $35 \%$ in the size of the ovary, and (c) a more uniform surface texture than was apparent on the ovary lacking the preovulatory follicle (P1. 1, Figs 1 and 2).

Within $30 \mathrm{hr}$ of ovulation, a stellate pattern of blood vessels was seen on a

\section{EXPLANATION OF PLATE 1}

Frg. 1. Day 10 of cycle in $M$. fascicularis. The arrow marks the site of a developing follicle on the left ovary. Note the difference in colour and shape of the right ovary.

FIg. 2. Day 10 of cycle. The same stage of follicular development as on the left ovary in Fig. 1 but in another monkey. Note the grey area at the arrow indicating the site of a follicle.

Fig. 3. Day 11 of cycle. The stellate pattern of blood vessels established on the follicular wall. A: Vessel which will traverse the centre of follicle as development proceeds. B: Tissue which will form follicular hemispheres.

FIG. 4. Day 12 of cycle. The follicular cone is established. Note the vessel at the centre of the follicle (A) and the bifurcation at the edge of the follicle.

Fig. 5. Day 12, $4 \mathrm{hr}$ after Fig. 4. Note the formation of stigmata (arrows) and enlargement of the right hemisphere.

Fig. 6. Day 12, 2 hr after Fig. 5. Note the fimbria covering the enlarged hemisphere and the stigma. 


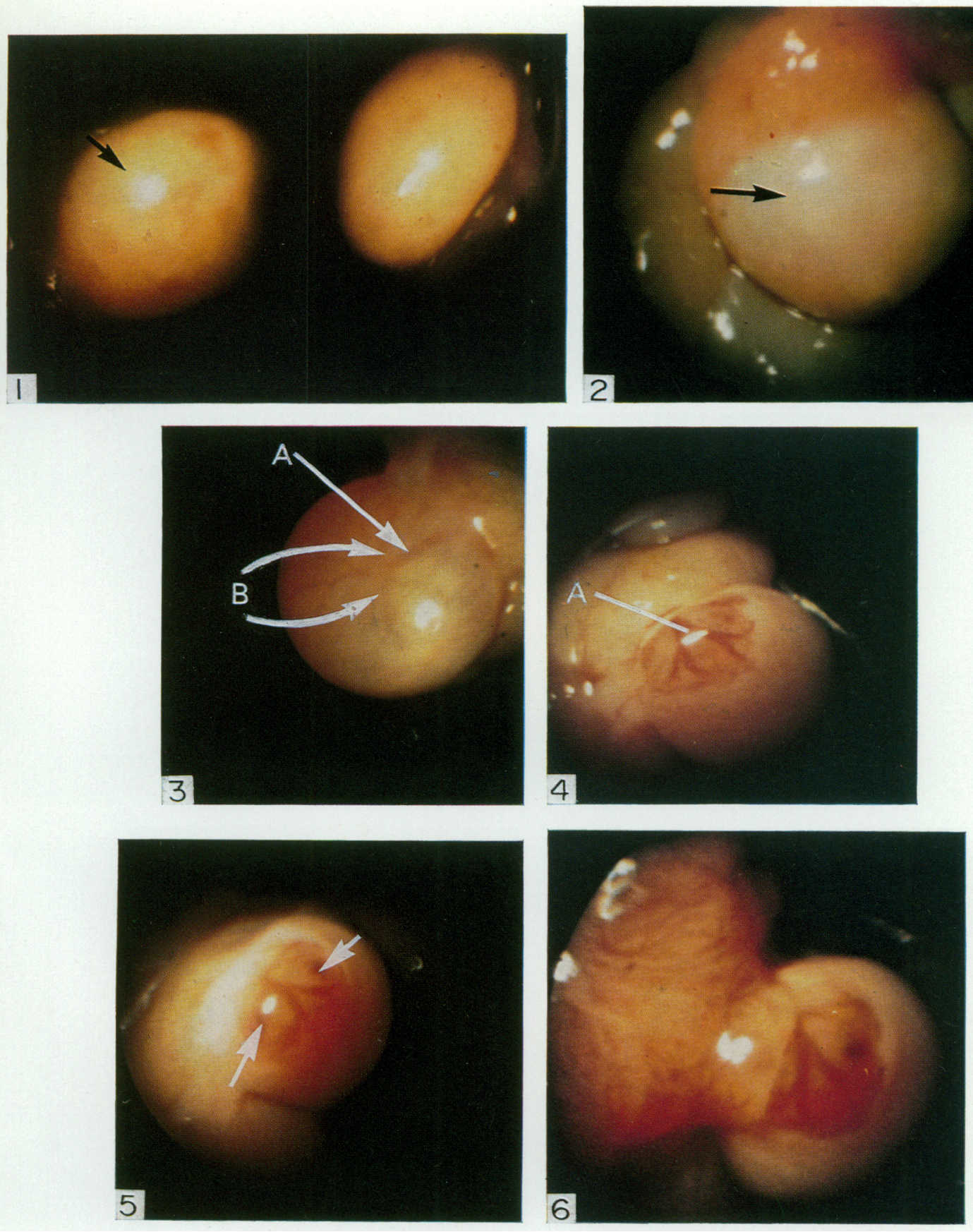

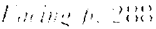



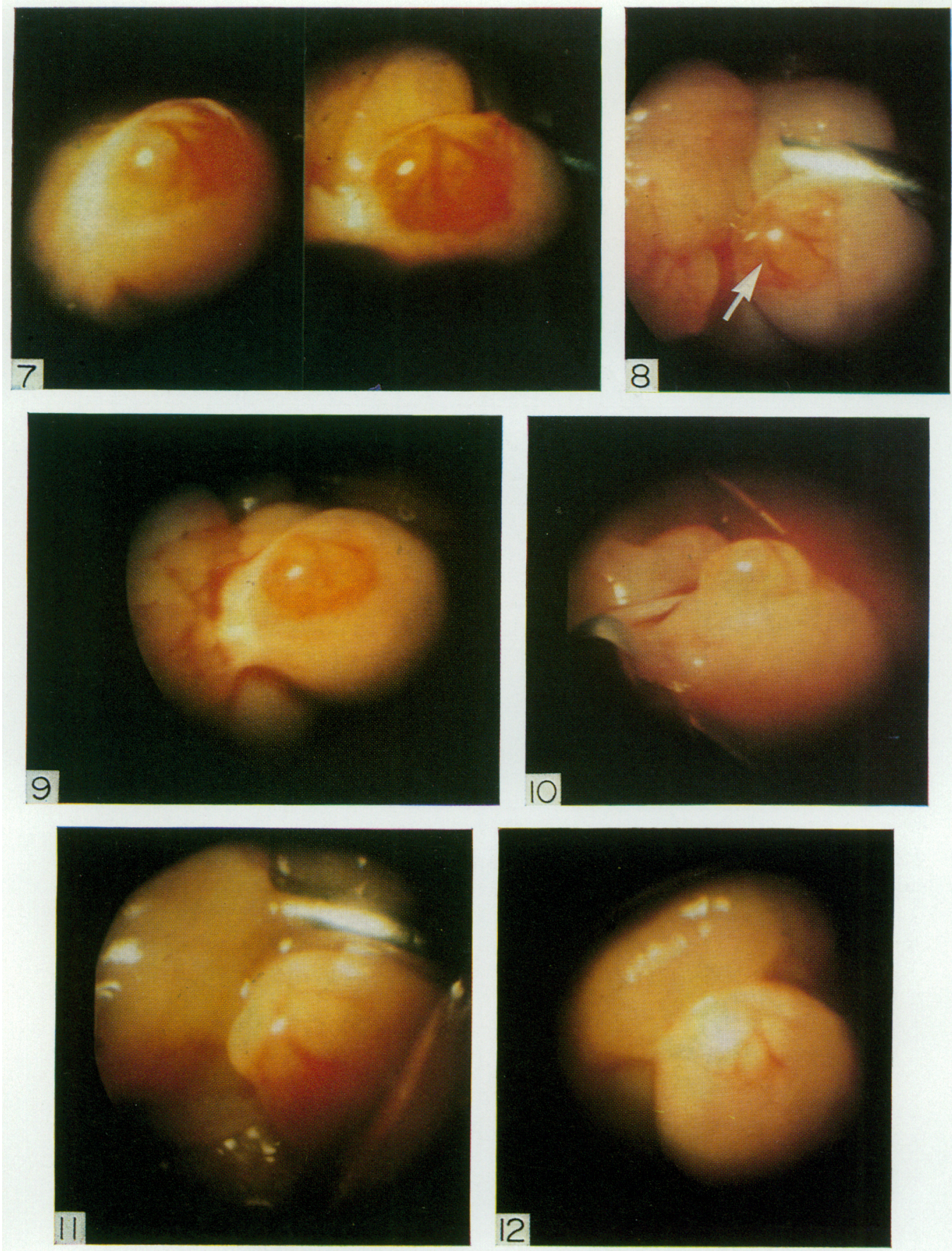

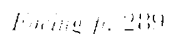


portion of the ovary which would eventually form the follicular wall (Pl. 1, Figs 3 and 4 ). Within 8 to $10 \mathrm{hr}$ of ovulation, the pattern of vessels became more pronounced and the follicular cone was established (Pl. 1, Fig. 4). In $80 \%$ of the cases, this pattern presented a network of small vessels around the base of the follicular cone and a large vessel across the centre of the follicular wall which bifurcated at the follicular border (Pl. 1, Figs 4 and 5; Pl. 2). The vessel across the centre of the follicle divided it into two hemispheres, each displaying a localized area of avascular tissue (stigmata) (Pl. I, Fig. 5; Pl. 2). In several cases, the fimbria approximated one of the follicular hemispheres (Pl. 1, Fig. 6).

The most significant postovulatory changes were (a) a generalized haemorrhagic appearance (Pl. 2, Fig. 7), (b) a loss of definition of the follicular vasculature (Pl. 2, Figs 7, 8 and 9), (c) the progressive occlusion of the stigmata (Pl. 2, Fig. 10), (d) a flattening, or irregularity of the follicular wall (PI. 2, Fig. 8), and (e) occlusion of the follicle (luteinization) (Pl. 2, Figs 9, 10 and 11). These characteristics could be observed as early as $10 \mathrm{hr}$ after ovulation, but the corpus haemorrhagicum generally could not be reliably distinguished from the preovulatory follicle until 20 to $40 \mathrm{hr}$ after ovulation.

In the majority of cases, the vasculature present in preovulatory follicles remained intact during the remainder of the cycle (Pl. 2, Figs 11 and 12).

Laparoscopy obviates the need to perform complete laparotomies in order to examine the reproductive tracts in primates.

The identification of the morphological development of the follicle in $M$. fascicularis has provided a valuable tool which can be used to identify early developing follicles, predict ovulation times, assist in the timing and recovery of ova by follicular aspiration and evaluate the effects of pharmacological agents on ovarian function.

The physiological significance of the highly specific and unique vascular pattern is unknown. One can speculate that they may serve as a delivery system for collagenases or other enzymes which may play a rôle in the mechanism of ovulation; or, perhaps the blocking of a specific vessel may result in a localized necrosis which might affect ovulation. The fact that such a distinctive anatomical pattern associated with follicular development has been identified, should be of assistance to future investigators concerned with the mechanism of ovulation.

\section{EXPLANATION OF PLATE 2}

FIG. 7. Postovulatory follicle on Day 14 on the right, compared to preovulatory follicle of Day 12 in $M$. fascicularis. Note the haemorrhagic appearance and loss of definition of the follicular vessels in the postovulatory follicle.

Fig. 8. Day 14 of the cycle. Note the irregularity on the follicular wall (arrow) where the wall is partially collapsed.

Frg. 9. Day 15 of cycle. The follicle is still haemorrhagic, and some luteinization is visible.

Fig. 10. Day 16 of cycle. The corpus luteum is assuming a nodular appearance. Occlusion of the stigmata is nearly complete.

FIG. 11. Day 20 of cycle. Further luteinization of the corpus luteum. The vascular pattern has begun to recede.

Fig. 12. Day 24 of cycle. Note the follicular vessel may persist through the end of a given cycle. 
This work was supported by NIH Contract No. 70-2061, from the Center for Population Research; USPHS Grant No. 5-P06-RR 00366-04, to the Center for Laboratory Animal Resources and NIH Research Career Development Award No. 1-K4-HD35, 306-01.

\section{REFERENCES}

Blandau, R. J. (1955) Ovulation in the living albino rat. Fert. Steril. 6, 391.

Dukelow, W. R., Jarosz, S. J., JewetT, D. A. \& Harrison, R. M. (1971) Laparoscopic examination of the ovaries in goats and primates. Lab. Anim. Sci. 21, 594.

JewetT, D. A. \& Dukelow, W. R. (1971a) Follicular morphology in Macaca fascicularis. Folia primatol. $16,216$.

JewetT, D. A. \& Dukelow, W. R. (1971b) Laparoscopy and precise mating techniques to determine gestation length in Macaca fascicularis. Lab. Primate Newsletter, 10, 16.

Jewett, D. A. \& Dukelow, W. R. (1972) Cyclicity and gestation length of Macaca fascicularis. Primates, $13,327$.

Semm, K. (1969) Gynaecological pelviscopy and its instrumentarium. Acta fertil, europ. 1, 81. 